\section{No Need for Root Replacement}

Explantation of a SAPIEN valve is feasible, followed by standard AVR without root replacement. In contrast, other transcatheter valves more broadly fixed to the left ventricular outflow tract, root, and/or tubular aorta might require more complex high-risk operations after explantation.

\section{Valve Stability and Pseudoendothelialization}

Fears of calcium resorption leading to loss of valve fixation over the intermediate term are likely unfounded. In this patient, despite minimal initial native aortic cusp calcification, the valve was tenaciously fixed. Whether tissue in-growth contributed is unclear. This valve, particularly the uncovered upper stent cells, was not fully covered in pseudoendothelium 11 months later. Although beneficial near the coronary ostia (possibly caused by high flow), retarded pseudoendothelialization might require antiplatelet therapy postoperatively. Paravalvular leak might further disrupt tissue coverage. Finally, cusp integrity was lost early, probably accelerated by infection and high flow with (paravalvular) AR. Further evaluation of long-term durability, function, and tissue coverage is needed.

We thank Lise Matzke for assistance with obtaining the light micrograph and gross specimen images.

\section{References}

1. Webb JG, Chandavimol M, Thompson CR, Ricci DR, Carere RG, Munt BI, et al. Percutaneous aortic valve implantation retrograde from the femoral artery. Circulation. 2006;113:842-50.

2. Lichtenstein SV, Cheung A, Ye J, Thompson CR, Carere RG, Pasupati S, et al Transapical transcatheter aortic valve implantation in humans: initial clinical experience. Circulation. 2006;114:591-6.

3. Pasupati S, Sinhal A, Humphries K, Ivens E, Moss R, Thompson CR, et al. Re-dilation of balloon expandable aortic valves [BEAV]: what do we know? Am J Cardiol. 2007;100(suppl I):57L.

4. Hanzel GS, Harrity PJ, Schreiber TL, O’Neill WW. Retrograde percutaneous aortic valve implantation for critical aortic stenosis. Catheter Cardiovasc Interv. 2005;64: 322-6.

5. Raval AN, Menkis AH, Boughner DR. Mitral valve aneurysm associated with aortic valve endocarditis and regurgitation. Heart Surg Forum. 2002;5:298-9.

\title{
A new subspecialty in cardiac surgery: Scrap metal merchant
}

\author{
Giuseppe Rescigno, MD, ${ }^{\mathrm{a}}$ Marco Pozzi, MD, FRCS, FETCS, ${ }^{\mathrm{a}}$ Filippo Capestro, MD, ${ }^{\mathrm{a}}$ Luciano S. Matteucci, MD, ${ }^{\mathrm{a}}$ \\ Christopher Münch, MD, ${ }^{\mathrm{b}}$ Gianfranco Iacobone, MD, ${ }^{\mathrm{a}}$ and Gian Piero Piccoli, MD, ${ }^{\mathrm{a}}$ Ancona, Italy
}

The future of cardiac surgery is an ongoing debate, prompted by the dramatic development of percutaneous techniques that actually reduce the indications for standard surgical treatments. ${ }^{1,2}$ During the last 6 months, we have been faced with 4 cases of complications from percutaneous procedures related to entrapment of foreign bodies or lesions due to mechanical devices. Our main goal has been to retrieve these devices and treat the underlying cardiac disease.

\section{CLINICAL SUMMARIES Patient 1}

A 72-year-old man was scheduled for placement of elective left anterior descending artery stent in another hospital. The patient had an atheromatous left common trunk. During the procedure, the stent was entrapped at this level. The patient was therefore transferred to our hospital. Under cardiopulmonary bypass (CPB) and cardioplegic arrest, we

\footnotetext{
From the Departments of Cardiac Surgery ${ }^{\mathrm{a}}$ and Cardiac Anesthesia, ${ }^{\mathrm{b}}$ Lancisi HospitalOspedali Riuniti di Ancona, Ancona, Italy.

Received for publication Dec 29, 2007; accepted for publication Jan 8, 2008.

Address for reprints: Giuseppe Rescigno, MD, Via Santa Maria del Fiore 62, 60030

Morro d'Alba, Italy (E-mail: grescigno@libero.it).

J Thorac Cardiovasc Surg 2009;137:1549-50

0022-5223/\$36.00

Copyright (c) 2009 by The American Association for Thoracic Surgery

doi:10.1016/j.jtcvs.2008.01.049
}

removed the stent through the aorta (Figure 1). A complete revascularization was performed by means of bilateral internal thoracic artery grafting.

\section{Patient 2}

A 74-year-old man who had a percutaneous coronary intervention (PCI) on a diagonal branch was referred to our department because of an entrapped guide wire at the level of the left common trunk, despite the endovascular attempt to retrieve it. The patient was operated on, and under CPB and cardioplegic arrest, the guide wire was removed by a combined approach through the aorta and an arteriotomy of the diagonal vessel. A left internal thoracic artery graft was therefore implanted on the diagonal branch.

\section{Patient 3}

A 65-year-old man was admitted to our surgical department with chest pain. He had undergone a transcatheter patent forame ovale closure with a 25-mm Amplatzer occluder 1 year prior. The transesophageal echocardiogram (TEE) performed showed "penetration" of the left atrial disk of the occluder into the left atrial wall and the posterior wall of the aortic root. A magnetic resonance image demonstrated an extravasation of the dye from the left atrial cavity into the 


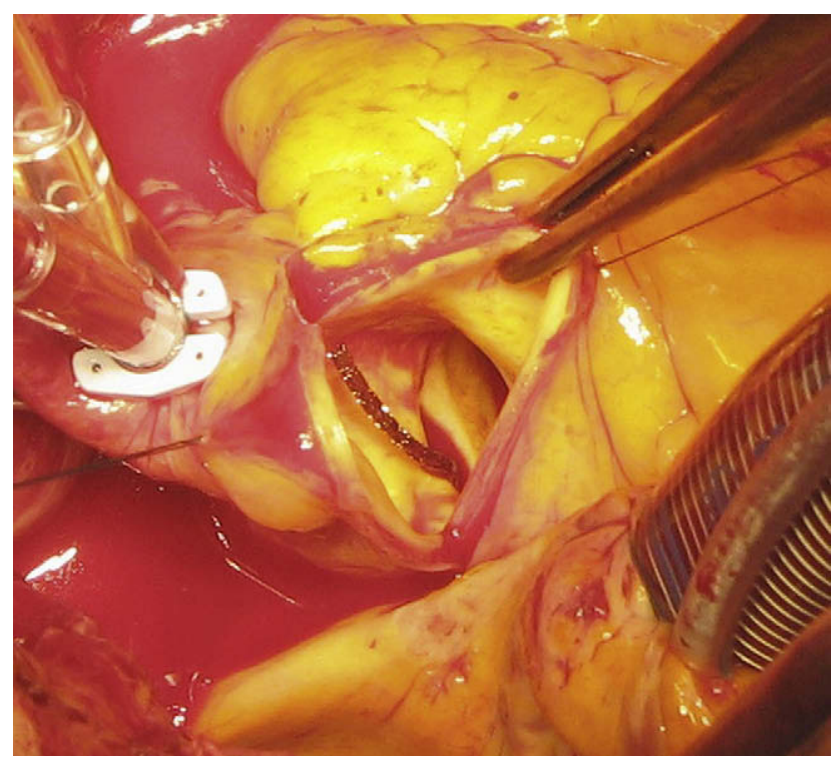

FIGURE 1. The entrapped stent is easily visible in the left main common trunk (patient 1).

pericardium. The patient was subsequently operated on; the device was removed and the defect repaired by direct suture. A small perforation $(3 \mathrm{~mm})$ of the atrial wall was found, together with an erosion of the adventitia and the media of the aortic root (Figure 2). The left atrium and the aorta were repaired by means of multiple sutures reinforced with pledgets.

\section{Patient 4}

A 43-year-old woman underwent a follow-up control (12 months) post-Amplatzer device implantation for atrial septal defect closure. Echo and angiographic data showed that the device deeply imprinted the aortic root, which was significantly thinned $(1 \mathrm{~mm})$. The device was removed and the aorta was reinforced with autologous pericardial patch. The postoperative course was uneventful in all the patients.

\section{DISCUSSION}

The past 10 years have been characterized by a progressive reduction of cardiac surgical procedures, mainly due to the availability of more effective percutaneous interventions. An important aspect concerns the potential complications of these new technological procedures. ${ }^{3-5}$ These are often related to entrapped metallic devices in cardiac chambers or vessels as in our patients 1 and 2 or to erosion of cardiac structures as in patients 3 and 4 . In the former condition, an emergency operation is always mandatory. When the patient has to be transferred from another hospital, great care should be taken to avoid any dislodgement of the intra-

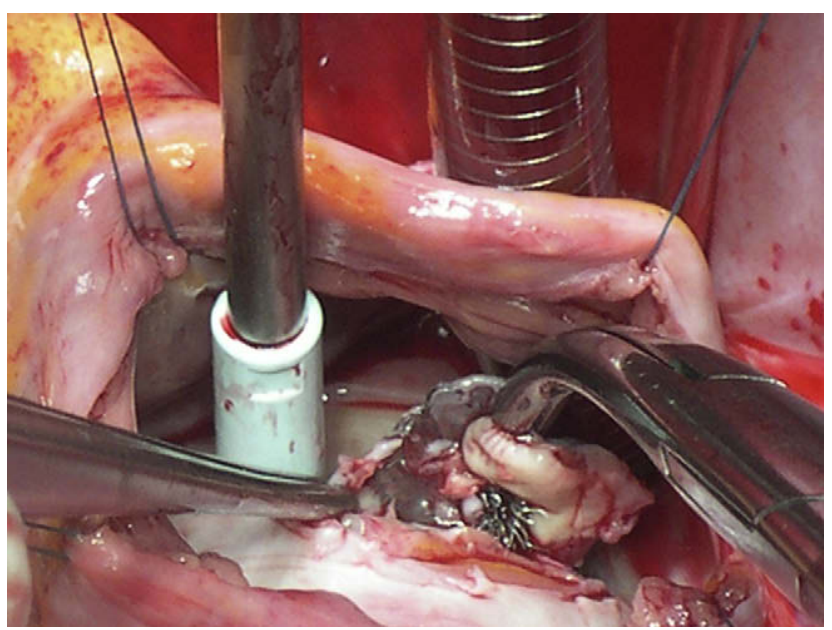

FIGURE 2. Intraoperative view showing the removal of Amplatzer device (patient 3).

vascular devices. An effective anticoagulation regimen is also advisable. The operation should be carefully planned, considering that any heart manipulation may dislodge the stent or create additional damage to cardiac structures. In patient 1 , the stent was removed quite easily through the aortotomy, before proceeding to the complete revascularization. In patient 2 , on the contrary, the guide wire removal was technically challenging and required a combined approach through the aortotomy and the coronary incision. The maneuvers always create additional dissection or lesions to the involved vessel.

When the indication to operate is a progressive erosion of cardiac structures, as for patient 4 , the operation may be performed more electively. Once again careful decision making is advised.

In conclusion, we believe that cardiac surgeons will be inevitably faced with these kinds of clinical conditions and should be prepared to treat them effectively. Those surgeons who gain the skills to perform percutaneous procedures will have the advantage over other interventional specialists to be able to treat their complications immediately and by themselves.

\section{References}

1. Mohr F. Viewpoint: The future of cardiac surgery. Interview by Mark Nicholls. Circulation. 2006;114:f190-1.

2. Lytle B, Mack M. The future of cardiac surgery: the times, they are a changin'. Ann Thorac Surg. 2005;79:1470-2.

3. Singh J, Thingnam SK, Das D, Singh H, Sharma R, Vijayvergia R. Surgical removal of entrapped and broken percutaneous transluminal coronary angioplasty balloon catheter. Interact Cardiovasc Thorac Surg. 2007;6:94-6.

4. Luthra S, Tatoulis J, Warren RJ. Drug-eluting stent-induced left anterior descending coronary artery aneurysm: repair by pericardial patch-where are we headed? Ann Thorac Surg. 2007;83:1530-2.

5. Shirakabe A, Takano H, Nakamura S, Kikuchi A, Sasaki A, Yamamoto E, et al. Coronary perforation during percutaneous coronary intervention. Int Heart J. 2007;48:1-9. 